\title{
REALTIME MONITORING OF PIPELINES FOR THIRD-PARTY CONTACT
}

\section{SEMI-ANNUAL TECHNICAL PROGRESS REPORT NO. 2 April 1, 2004-September 30, 2004}

\section{Principal Authors}

Gary L. Burkhardt, Staff Scientist Alfred E. Crouch, Staff Engineer

Cooperative Agreement DE-FC26-03NT41878 Southwest Research Institute ${ }^{\circledR}$ Project 14.10211

\section{Submitting Organization}

Sensor Systems and NDE Technology Department

Applied Physics Division

Southwest Research Institute

6220 Culebra Road

San Antonio, Texas 78238

\section{Prepared for}

U.S. Department of Energy

National Energy Technology Lab

3610 Collins Ferry Road

Morgantown, West Virginia 26507-0880

October 2004

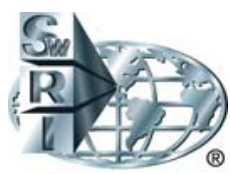




\section{DISCLAIMER}

This report was prepared as an account of work sponsored by an agency of the United States Government. Neither the United States Government nor any agency thereof, nor any of their employees, makes any warranty, express or implied, or assumes any legal liability or responsibility for the accuracy, completeness, or usefulness of any information, apparatus, product, or process disclosed, or represents that its use would not infringe privately owned rights. Reference herein to any specific commercial product, process, or service by trade name, trademark, or manufacturer or otherwise does not necessarily constitute or imply its endorsement, recommendation, or favoring by the United States Government or any agency thereof. The views and opinions of authors expressed herein do not necessarily state or reflect those of the United States Government or any agency thereof. 


\begin{abstract}
Third-party contact with pipelines (typically caused by contact with a digging or drilling device) can result in mechanical damage to the pipe, in addition to coating damage that can initiate corrosion. Because this type of damage often goes unreported and can lead to eventual catastrophic failure of the pipe, a reliable, cost-effective method is needed for monitoring and reporting third-party contact events.

The impressed alternating cycle current (IACC) pipeline monitoring method consists of impressing electrical signals on the pipe by generating a time-varying voltage between the pipe and the soil at periodic locations where pipeline access is available. The signal voltage between the pipe and ground is monitored continuously at receiving stations located some distance away. Thirdparty contact to the pipe that breaks through the coating changes the signal received at the receiving stations.

In this project, the IACC monitoring method is being developed, tested, and demonstrated. Work performed to date includes (1) a technology assessment, (2) development of an IACC model to predict performance and assist with selection of signal operating parameters, (3) Investigation of potential interactions with cathodic protection systems, and (4) experimental measurements on buried pipe at a test site as well as on an operating pipeline. Initial results show that simulated contact can be detected. Future work will involve further refinement of the method and testing on operating pipelines.
\end{abstract}




\section{TABLE OF CONTENTS}

Page

INTRODUCTION AND BACKGROUND ...................................................................... 1

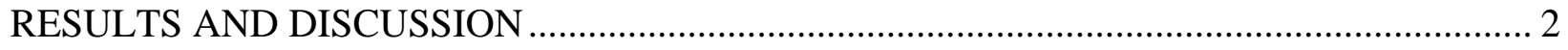

1.1 Research Management Plan .................................................................................... 2

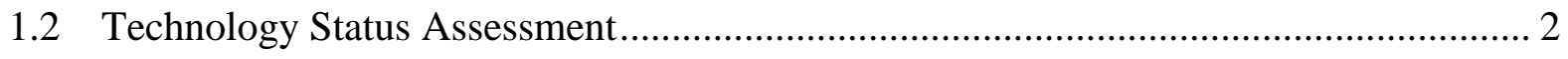

1.3 IACC Parameter Refinement .............................................................................. 2

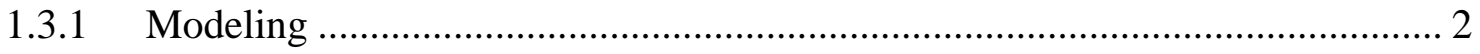

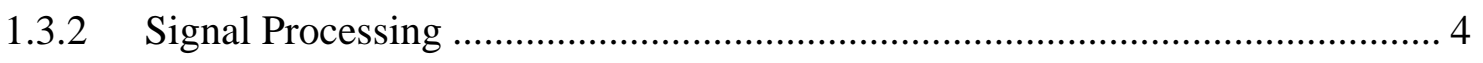

1.3.3 Experimental Evaluations........................................................................ 4

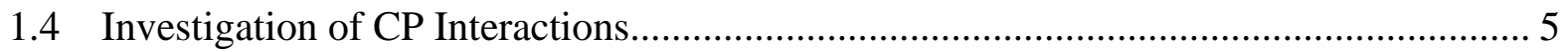

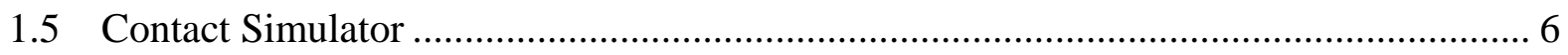

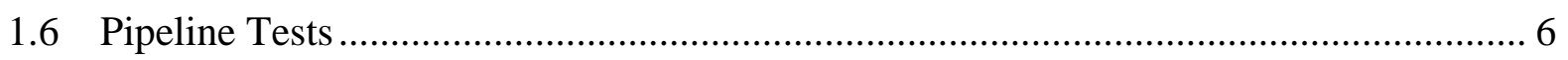

1.6.1 Measurement of Earth Resistance ............................................................ 7

1.6.2 Measurement of Pipe Parameters ........................................................... 8

1.6.3 Detection of Impressed Waveforms ........................................................... 8

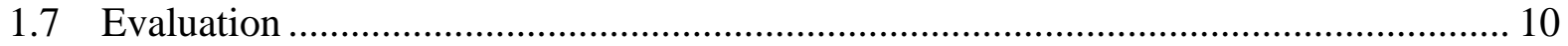

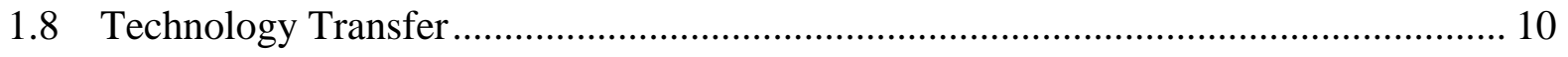

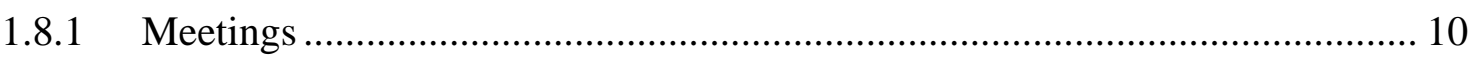

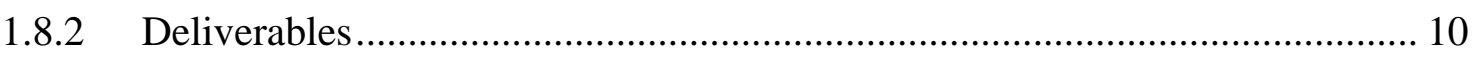

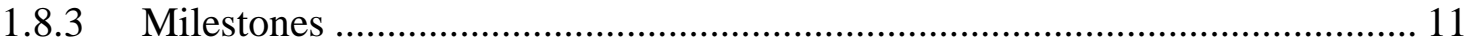

WORK ANTICIPATED IN NEXT REPORTING PERIOD ............................................. 11

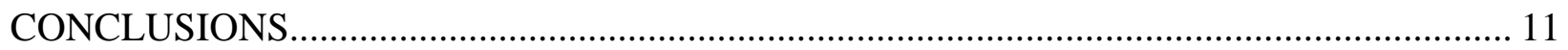

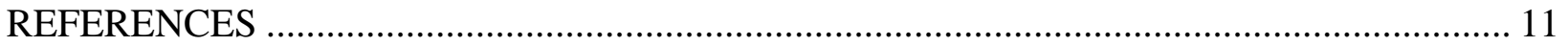




\section{LIST OF FIGURES}

$\underline{\text { Figure }}$

$\underline{\text { Page }}$

1 Schematic of IACC transmit station (left), showing time-varying voltage applied to the pipe, and receive station (right), showing measurement of pipe-to-soil voltage waveform .............................................................................

2 PCAD model of SwRI test pipe: (a) normal pipe condition; (b) with

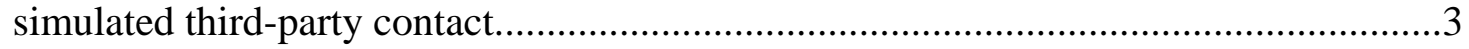

3 Pipeline plan view showing location risers and ground rods ....................................5

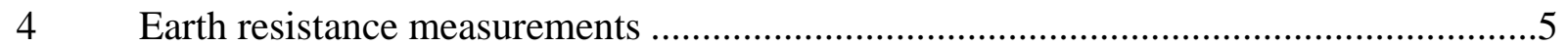

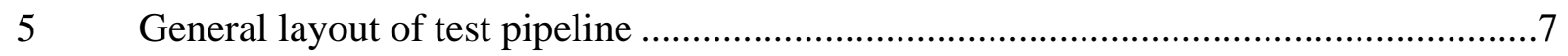

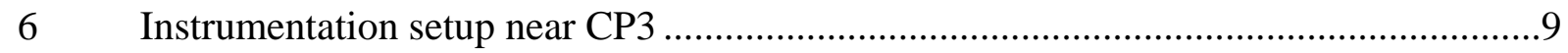

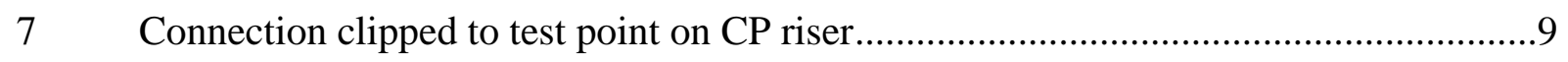

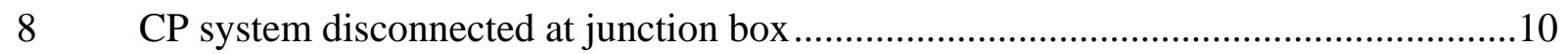




\section{INTRODUCTION AND BACKGROUND}

Third-party contact with pipelines (typically caused by contact with a digging or drilling device) can result in mechanical damage to the pipe. Because this type of damage often goes unreported and can lead to eventual catastrophic failure of the pipe, a reliable, cost-effective method is needed for monitoring and reporting third-party contact events.

The impressed alternating cycle current (IACC) pipeline monitoring method involves impressing electrical signals on the pipe by generating a time-varying voltage between the pipe and the soil at periodic locations where pipeline access is available (Figure 1). The signal, which travels down the pipe in both directions from the transmitter (Figure 1, left), consists of a time-dependent waveform designed to maximize IACC system performance in the presence of various sources of external noise. The signal voltage between the pipe and ground is monitored continuously at this transmission station. In addition, neighboring receiving stations with similar configurations (Figure 1, right), located at some distance from the transmitting station, continuously monitor the received signal by measuring the pipe-to-soil voltage waveform. Third-party contact to the pipe that breaks through the coating changes (1) the impedance seen by the transmitting station and/or (2) the signal received at the IACC receiving stations that are located in the segment of pipe being contacted.
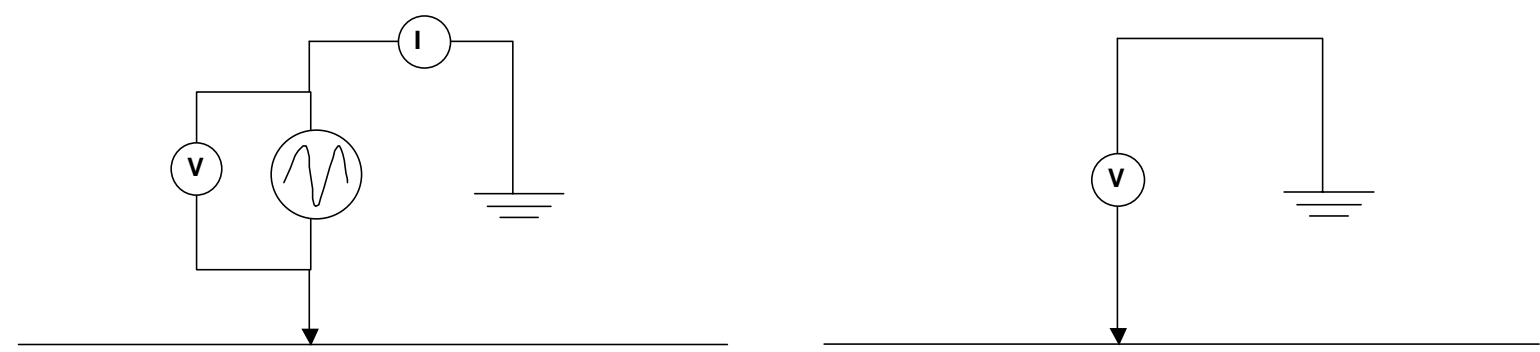

Figure 1. Schematic of IACC transmit station (left), showing time-varying voltage applied to the pipe, and receive station (right), showing measurement of pipe-to-soil voltage waveform

The objectives of the proposed work are to further develop, test, and demonstrate the IACC monitoring method for detecting third-party contact with pipelines in real time. This method will allow existing pipelines to be retrofitted for monitoring without excavation because the technique uses existing cathodic protection (CP) test points. In addition, the method could be readily applied to new pipelines. Upon completion of the work, guidelines will be developed for use by a vendor to begin development of a commercial version of an IACC system. 


\section{RESULTS AND DISCUSSION}

The sections and corresponding numbers below correspond to those used on the Research Management Plan.

\subsection{Research Management Plan}

A research management plan document was prepared and submitted during the previous reporting period.

\subsection{Technology Status Assessment}

A technology status assessment was prepared and submitted during the previous reporting period.

\subsection{IACC Parameter Refinement}

\subsubsection{Modeling}

This effort involves developing an equivalent circuit computer model to represent the electrical circuit formed by the pipe and its interaction with the earth (e.g. resistive and capacitative coupling). The model allows simulations to be performed to study the effects of signal characteristics (e.g. frequencies and excitation levels) on the IACC signals. These simulations will allow signal characteristics to be selected to maximize range and reduce interference.

PCAD Model Configuration-As discussed in the previous report, an equivalent circuit lumped parameter model was set up in PCAD (a circuit analysis software package) that will allow evaluation of the pipe response at different excitation frequencies. The model configuration is shown in Figure 2 and is based on the configuration and measured parameters of the pipe at the SwRI test site (Section 1.3.3 in the previous report). The model is similar to that reported previously, except that modifications were made to the soil resistance in the return paths to account for the results of new measurements that show that soil resistance is mostly a function of contact resistance and not strongly dependent on distance. Each section of the model represents the section of pipe between two risers in the test pipe. Note that the distances between the risers are different and the parameters for each section are scaled to the appropriate distance. The model represents an IACC monitoring system with the excitation at the left $\left(\mathrm{V}_{\text {in }}\right)$ and sensing at the right (OUT). Figure 2(b) shows a third-party contact event represented by a path to ground through the added resistor R9. The model can be extended and the parameters varied to represent pipelines of different lengths and diameters and in different soil conditions.

The output voltage was calculated at different frequencies ranging from $50 \mathrm{~Hz}$ to $5 \mathrm{kHz}$ for the 120 -foot-long test pipe. The absolute signal level (without contact) at $5 \mathrm{kHz}$ decreased by about 16 percent compared to $50 \mathrm{~Hz}$. Because the pipe is so short, the frequency effect was expected to be minimal, as predicted by the model. Simulated third-party contact resulted in a decrease in signal level of about 46 percent at $50 \mathrm{~Hz}$ to 28 percent at $5 \mathrm{kHz}$, thus indicating that contact could readily be detected. The pipe parameters were then adjusted to 


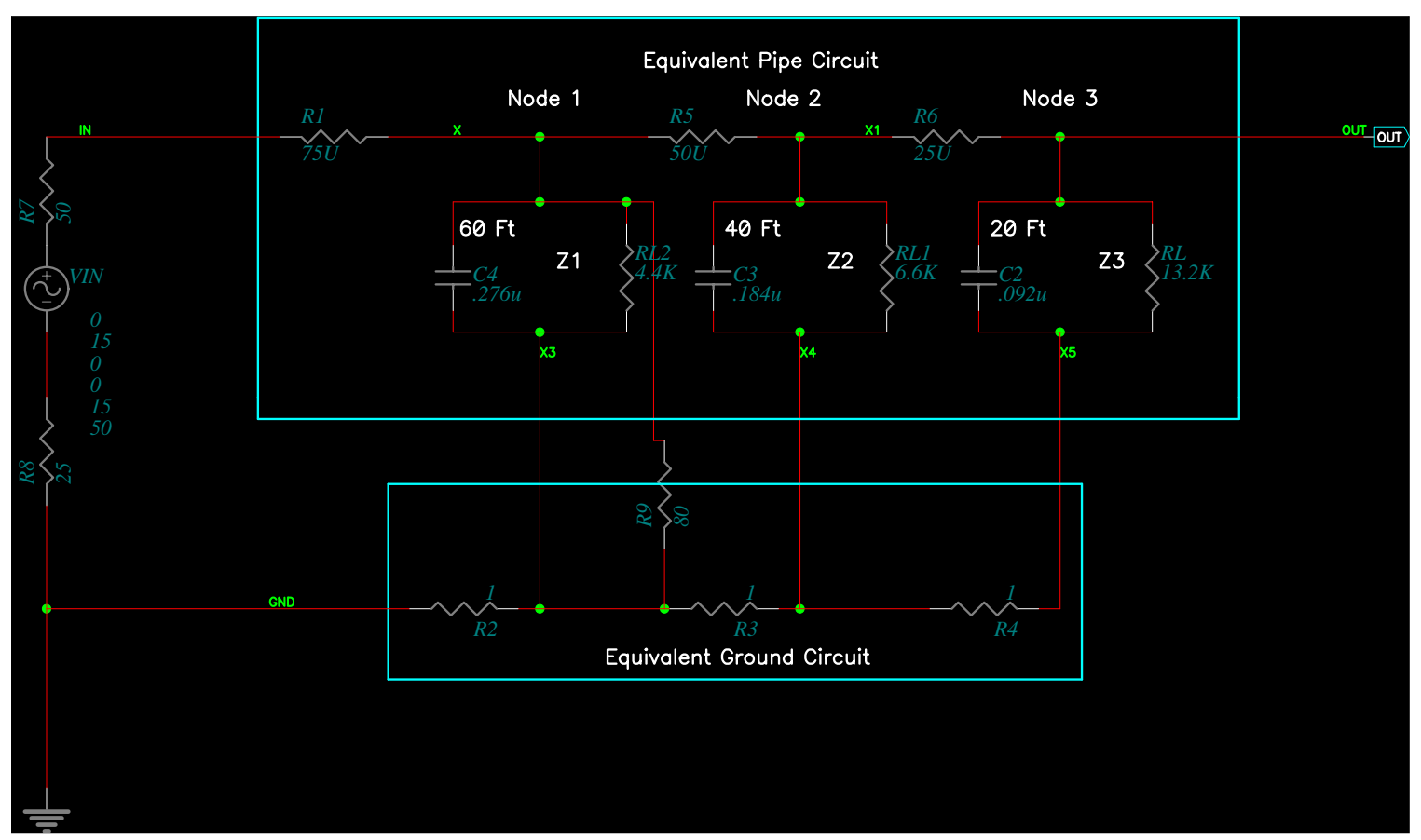

(a)

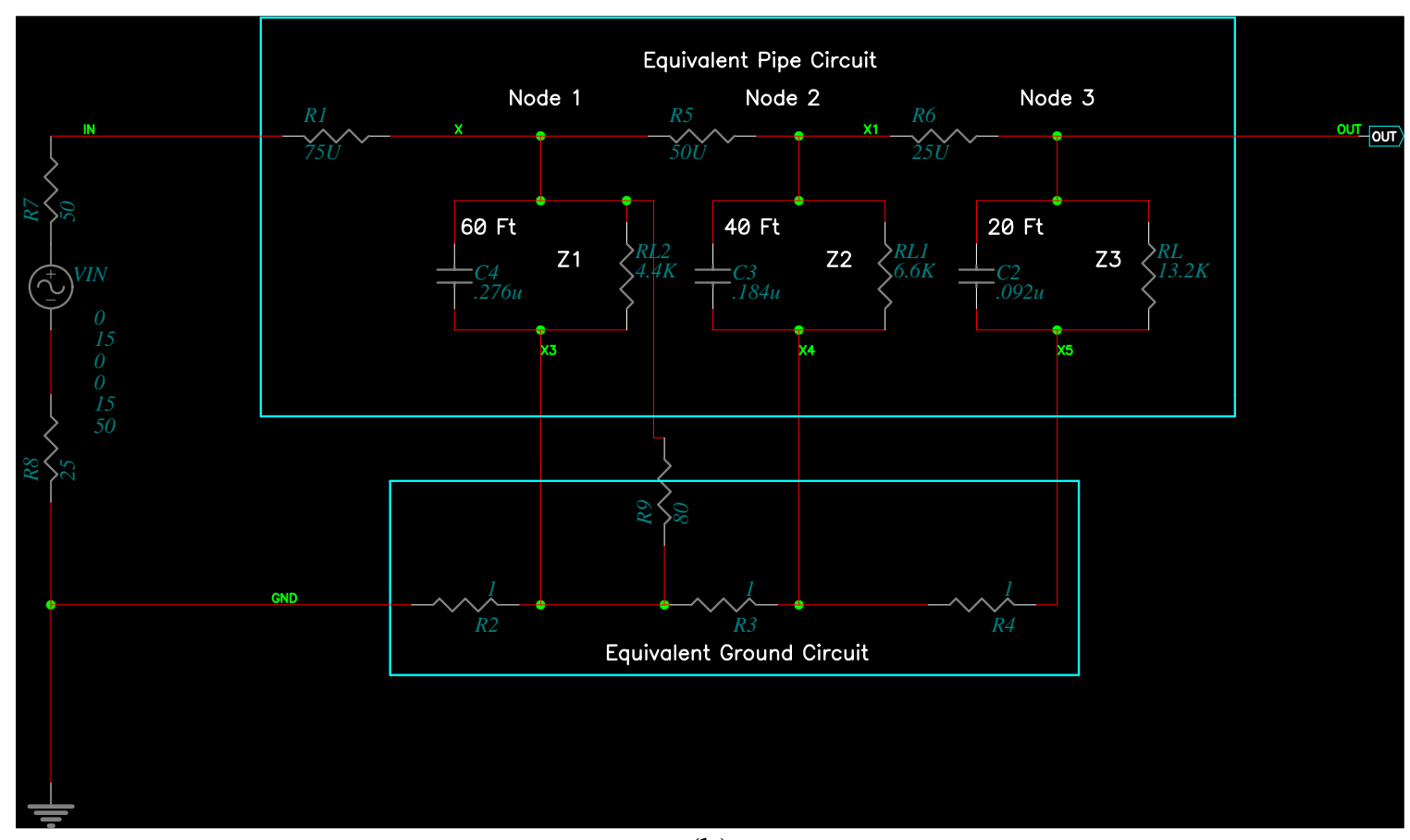

(b)

Figure 2. PCAD model of SwRI test pipe: (a) normal pipe condition;

(b) with simulated third-party contact 
simulate a 6,000-foot pipe. Under these conditions, the absolute signal level (without contact) at $5 \mathrm{kHz}$ decreased by about 93 percent compared to $50 \mathrm{~Hz}$. At $50 \mathrm{~Hz}$, the change due to contact was still relatively large (27 percent); however, at $500 \mathrm{~Hz}$ up to $5 \mathrm{kHz}$, there was essentially no change due to contact. These results indicate that for longer pipe distances, the excitation frequency needs to be relatively low, probably below $500 \mathrm{~Hz}$.

\subsubsection{Signal Processing}

The goal of the signal processing is to provide improved signal-to-noise ratios for the data so that sensing of third-party contact can be extended over longer distances. The signal processing approach consists of bandpass and notch filtering, as well as matched filtering operating on a chirp waveform. The matched filtering approach consists of comparing a waveform having the characteristics of the transmit waveform to that of the received waveform, similar to performing a cross correlation. A "match" between the waveforms produces a high correlation coefficient. By using a chirp, the signal is spread over a wide range of frequencies, thus reducing the effect of interfering noise at specific frequencies.

An additional processing approach is also being evaluated. This involves system identification using an auto-regressive parameter estimation technique. With this technique, the processing calculates an equivalent circuit and its electrical parameters (e.g. resistance and capacitance) for the pipe based on analysis of the data and behavior as a function of frequency. Changes in parameters specific to third-party contact are then identified. These parameters are monitored to determine if contact has occurred. This could provide an approach that is more sensitive to contact and less sensitive to other noise sources.

Both processes were tested on data from the SwRI test pipe. Because the pipe is short and the signals are strong, and because there is little change in frequency response over the length of this pipe, evaluation of the signal processing approaches on this pipe are not realistic for the longer distances that are the target in this project. As described in Section 1.6, data have now been obtained from an operating pipeline over a distance of 3,634 feet. The signal processing approaches are now being tested on these data.

\subsubsection{Experimental Evaluations}

The purpose of the experimental evaluations is to measure input parameters for the model, verify the model, and test signal parameters and signal-processing approaches. Experiments were conducted at the existing test site (shown in Figure 3). This site contains a 150-mm (6-inch)-diameter, 37-m (120-foot)-long asphaltic coated pipe buried approximately $1 \mathrm{~m}$ (3 feet) deep (using standard industry practices) with four tape-insulated risers that extend above the soil surface. The risers can be used to inject signals and to generate ground shorts or partial shorts to simulate third-party contact.

In addition to the test site pipe parameters reported previously, measurements made at the SwRI test bed attempted to determine a relationship between earth resistance and distance. Several ground rods were installed with separations varying from 5 to $40 \mathrm{~m}$. Resistance measurements were made using a 12-VDC source and dropping resistors to avoid ground rod contact resistance problems. Calculations showed that the earth resistance did not relate to the distance between rods. The graph in Figure 4 illustrates the findings. 
Instrumentation

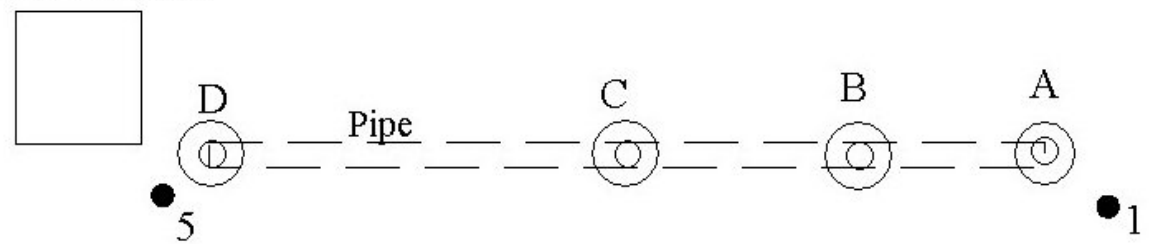

(O) Riser

- Ground Rods

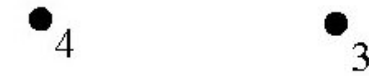

3

Figure 3. Pipeline plan view showing location risers and ground rods

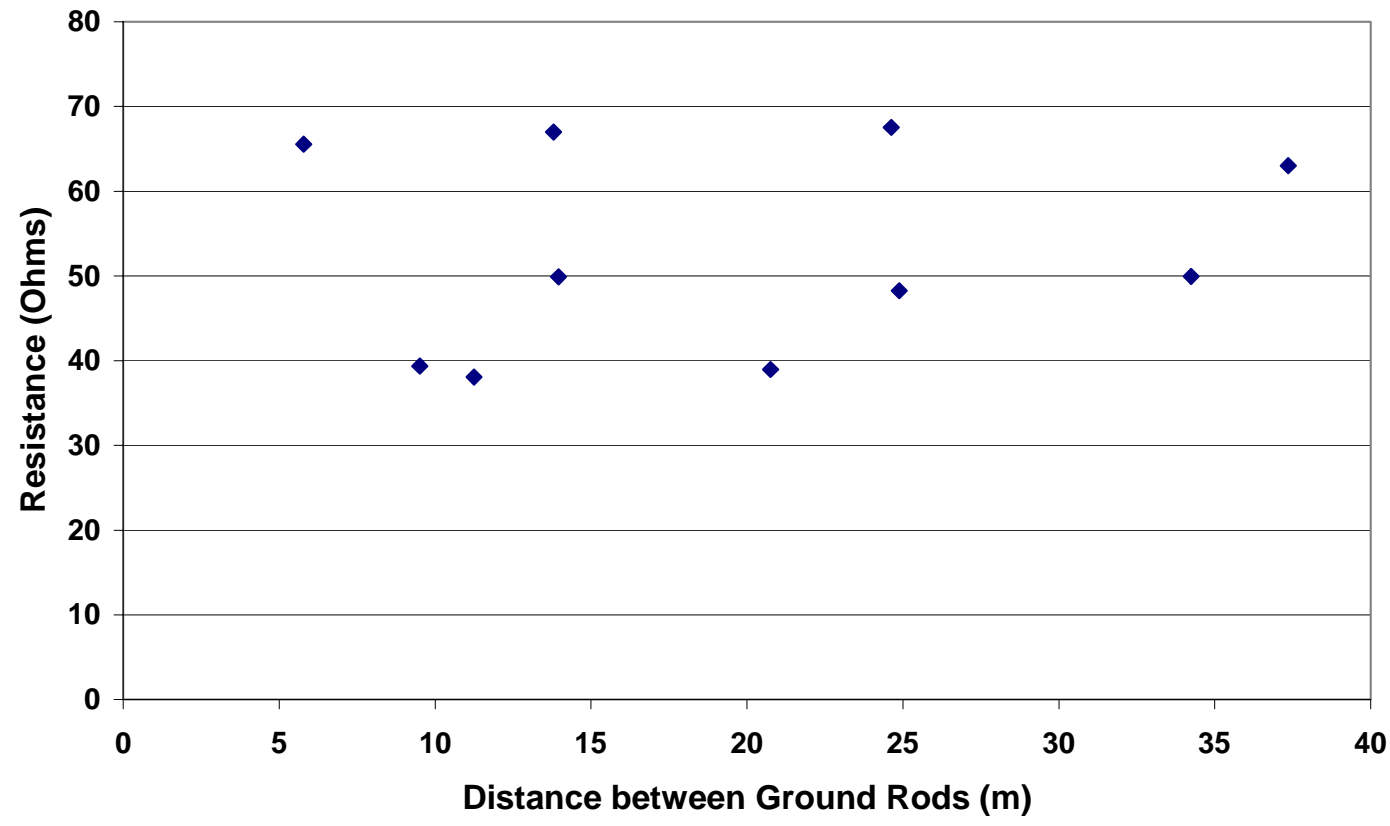

Figure 4. Earth resistance measurements

This finding was consistent with indications in the literature [1,2] that the resistance between two ground rods is most dependent on the ground rods, the soil conditions within a short distance of the rods, and not the distance between them.

\subsection{Investigation of CP Interactions}

The purpose of this task is to determine any effects of cathodic protection systems on the functioning of the IACC method and to determine any effects of the IACC signals on the CP system. As described in the previous report, both active and passive CP systems were installed on the SwRI test pipe so that experimental evaluations could be performed with either or none of the systems connected. 
Evaluation of the IACC approach on the SwRI test pipe showed that the active system introduced harmonics of $60 \mathrm{~Hz}$ on the test signal. The harmonics are generated from rectification of AC power to produce the DC voltage applied to the pipe. These harmonics can be removed from the IACC signals by notch filtering. As described in Section 1.6, additional data were obtained from an operating pipeline, both with and without the active CP system connected. These signals are currently being analyzed.

A CP specialist was contacted about potential unfavorable interactions between our chosen chirp signal and CP electronics. The following are the points he covered.

(1) We should keep the chirp signal amplitude below 15 VAC to avoid personnel shock hazard. This is the industry-accepted safe level for AC signals on a pipeline.

(2) An additional consideration for use of a strong AC signal is the concern over AC corrosion. It has been reported that induced AC currents from power lines can cause corrosion on a pipeline.

(3) One final consideration for applying AC to the pipeline is the effect it may have on measurements of $\mathrm{CP}$ potential during routine maintenance. Some instruments may not have enough AC rejection to allow them to measure the pipeline's DC voltage in the presence of the AC.

(4) Many CP systems use filtering (pure capacitive, inductive, or a network) to smooth out the surges of the full-wave rectified voltage. This is done largely to make the field measurements more accurate and stable. Capacitance across the CP output will show up as an increased capacitance of the pipeline to ground. This will attenuate our chirp signal. The estimate is that 5 percent of CP systems may have output capacitors.

(5) Most modern pipelines use impressed-current CP systems. Short pipeline segments and many older lines will have sacrificial anodes in place. These anodes represent a relatively direct short between the pipeline and ground. It may be that our system, once attached to the line, can be adjusted to allow for the anodes and still see the additional ground path produced by the third-party contact.

Discussions with the CP specialist (and possibly others) will continue in more detail.

\subsection{Contact Simulator}

The contact simulator was completed, as described in the previous report. Refinements to the simulator control program will be made to allow different simulated contact conditions to be evaluated.

\subsection{Pipeline Tests}

On September 28, 2004, a field test was conducted in cooperation with City Public Service (CPS) of San Antonio. CPS made available a 16-inch pipeline that feeds the Leon Creek Power Plant off Quintana Road on San Antonio’s southwest side. 
The pipeline is relatively new (less than 1 year) and has good fusion-bonded epoxy coating. Impressed current CP is in place. The total length of the line is approximately 8,500 feet. The soil was dry. The segment conveniently available for this first test measured 3,634 feet between their CP3 and CP5 test points. An intermediate test point (CP4) was 991 feet from CP3.

The test plan involved measurement of earth resistance between ground rods, measurement of pipeline parameters, and collecting data of the attenuation of a chirp test signal with the pipe open and then connected to ground at the intermediate test point. Measurements were to be made with the CP system activated and also with it disconnected.

\subsubsection{Measurement of Earth Resistance}

The general layout of the pipeline is shown in Figure 5. Approximate locations of CP test points are labeled 1 through 9. Four-foot-long, 3/4-inch-diameter, copper-plated ground rods were driven into the ground by $\mathrm{CP} 3, \mathrm{CP} 4$, and CP5. Care was taken to keep the rods away from the pipeline right-of-way to eliminate any chance that the rod could contact the pipe, even though the depth of burial was said to be greater than the 3-foot rod depth. CPS personnel pointed out the safe areas for installing the rods. The earth resistance was to be determined by causing low-voltage current to flow from a near rod to a remote rod through the earth and to return to the supply through a wire laid across country down the right-of-way. For this purpose, we supplied 4,000 feet of AWG 18 vinyl-insulated hook-up wire.

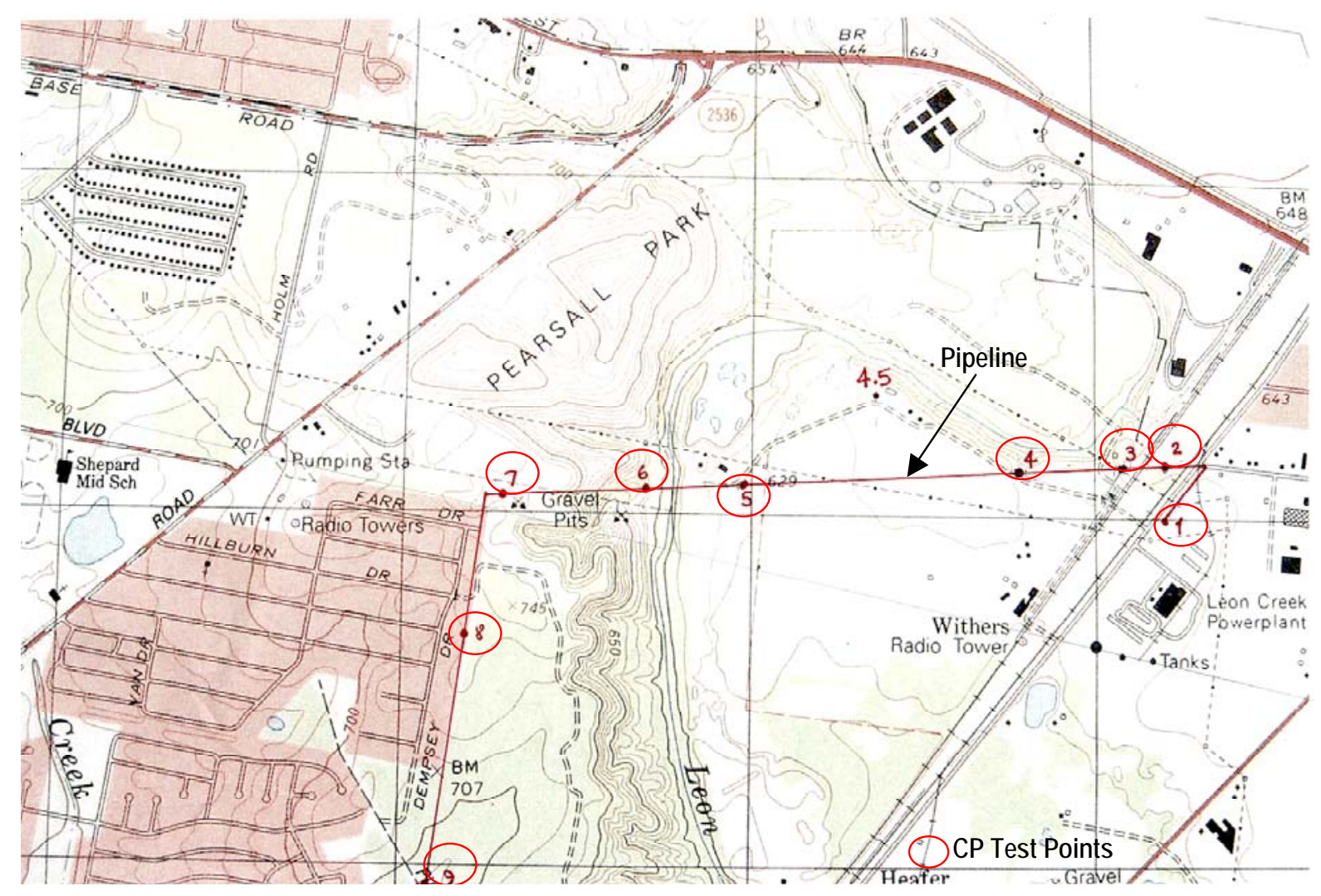

Figure 5. General layout of test pipeline 
results.

Measurements made between various combinations of rods yielded the following

\begin{tabular}{|c|c|}
\hline $\begin{array}{c}\text { Distance } \\
(\mathrm{ft})\end{array}$ & $\begin{array}{c}\text { Resistance } \\
\text { (ohms) }\end{array}$ \\
\hline 10 & 84.6 \\
\hline 991 & 118.3 \\
\hline 3634 & 162.6 \\
\hline
\end{tabular}

The conclusion drawn from these measurements was that earth resistance behaves as the SwRI tests led us to expect; that is, the controlling factor is the resistance between the rod and the immediate earth. The extended distance between rods is a much smaller influence on the total resistance.

\subsubsection{Measurement of Pipe Parameters}

The hook-up wire was used to complete a circuit between CP3 and CP5 through the pipe. Using the wire table resistance for AWG 18 wire, it was determined that the resistance of the pipe was 2.5 ohms for 3,600 feet. The accuracy of this measurement is questionable, since the pipe resistance is low compared to the hook-up wire, and the hook-up wire was not measured directly.

Two methods were used to determine the pipe-to-earth impedance. The LCR meter indicated 48-ohm resistance and 303-nF capacitance with the CP system connected. DC measurement with the 12-VDC source indicated resistance of 52.4 ohms. The CP system was then disconnected and the LCR reading taken again. This time, it indicated resistance of $3.46 \mathrm{kohms}$ and capacitance of $2.88 \mathrm{nF}$. It is suspected there is an unintended ground path at CP1 or CP9.

\subsubsection{Detection of Impressed Waveforms}

The final testing was to determine whether the $50-\mathrm{Hz}$ to $5-\mathrm{kHz}$ chirp could be detected at a remote location and whether grounding an intermediate point gave a recognizable change in the signal.

The chirp was first applied at CP3 using a signal generator set to 4 v. p-p. Signals were recorded at both CP3 and CP5. Transmit was then increased to $10 \mathrm{v}$. p-p and more data recorded. Background noise with the transmitter off was also recorded. CP4 was grounded and the test repeated. Measurements were made with the CP system ON and OFF.

To get a better signal-to-noise ratio, the Techron power amplifier was used at the transmit end to produce $78 \mathrm{v}$. p-p. New data were recorded for CP4 grounded and open. For all test conditions, five data sets were collected under identical conditions.

Figures 6 through 8 show the test setup. 


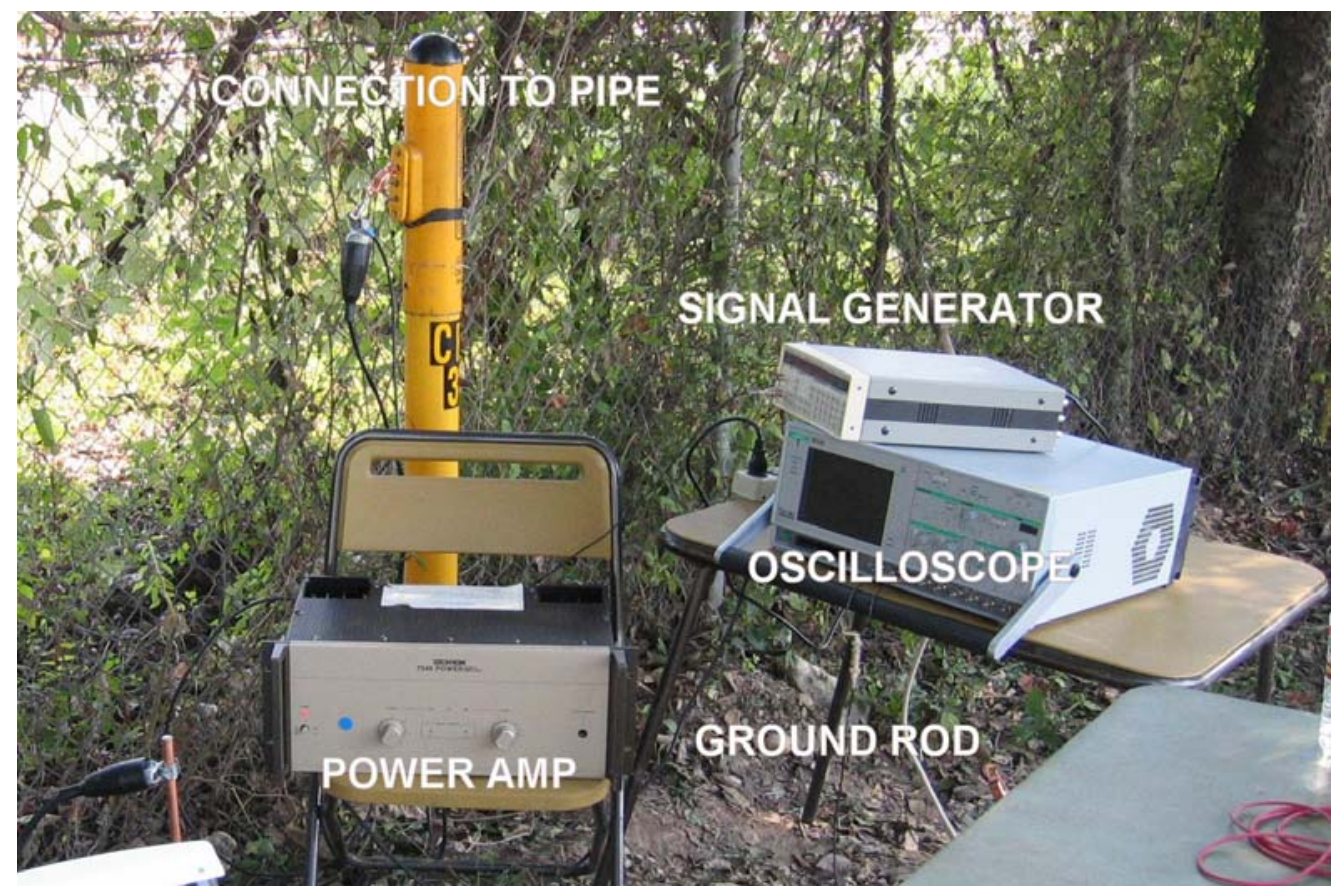

Figure 6. Instrumentation setup near CP3

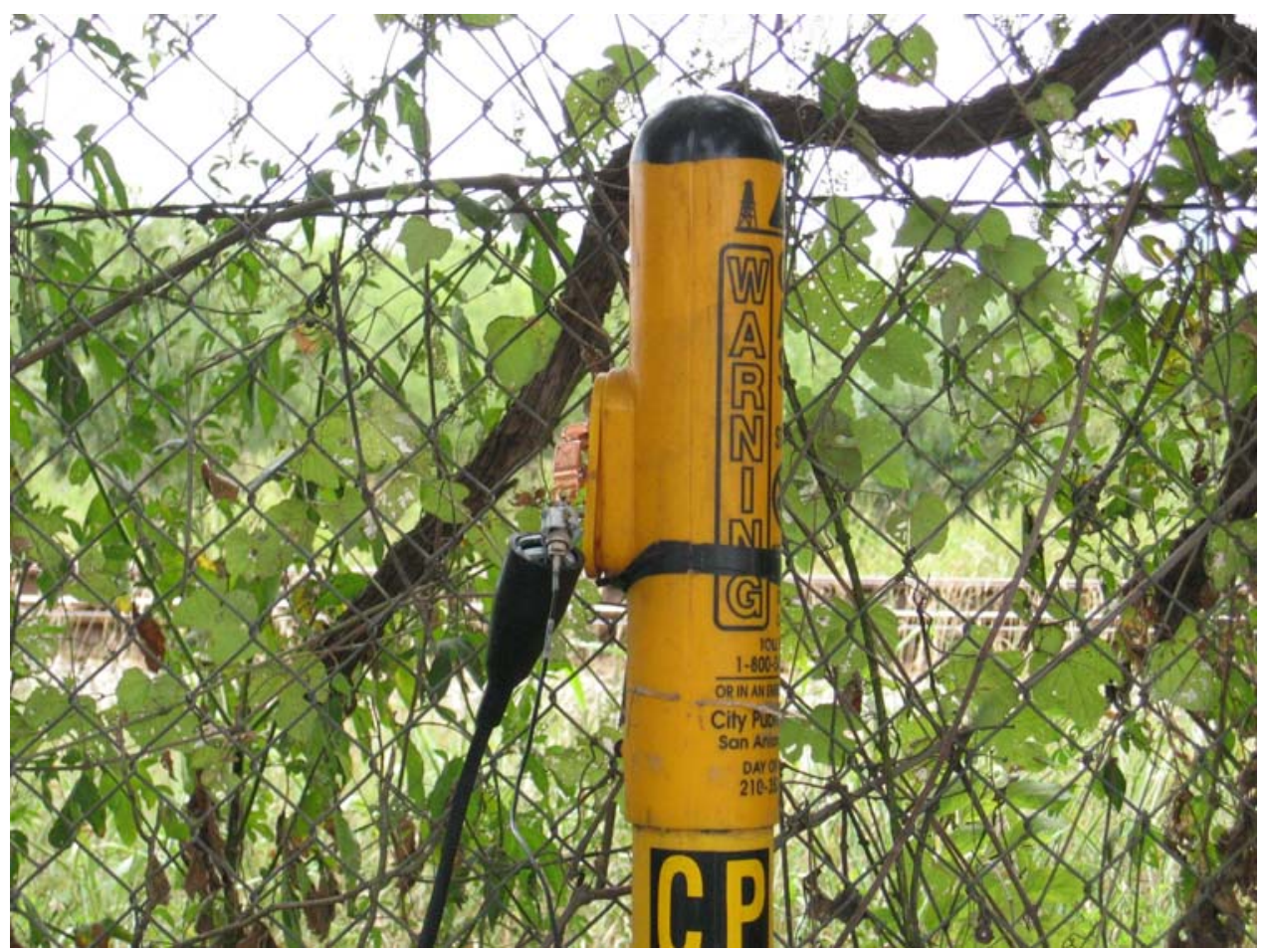

Figure 7. Connection clipped to test point on CP riser 


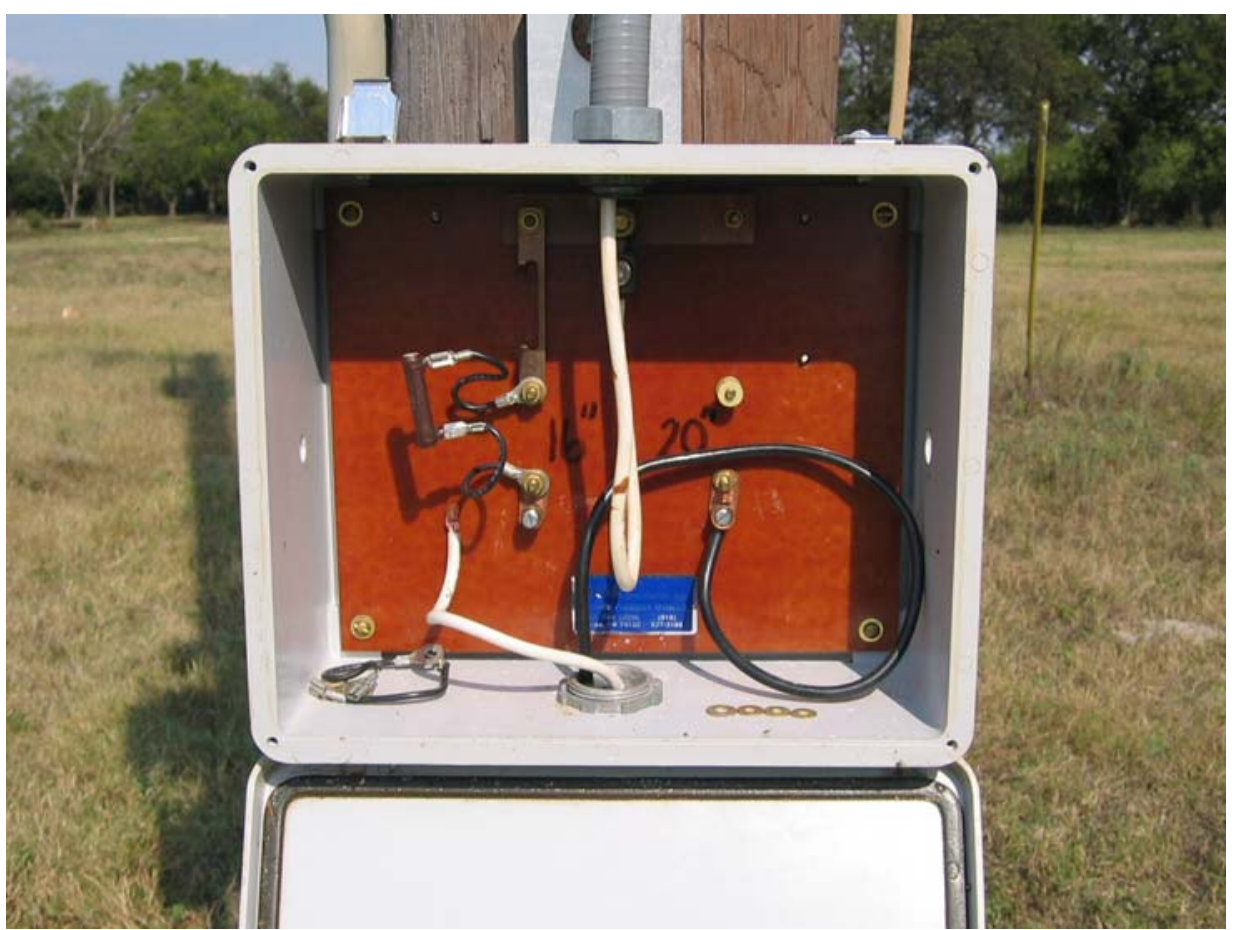

Figure 8. CP system disconnected at junction box

After all measurements were completed, the ground rods were removed, the CP system was reconnected, and the site was secured.

Data are currently being analyzed. Initial examination shows that a strong $60-\mathrm{Hz}$ signal with harmonics is present, even with the CP system disconnected. If filtering is applied, then the IACC signals are apparent at 3,634 feet, even with the lower amplitude drive signals.

\subsection{Evaluation}

No work was planned or accomplished.

\subsection{Technology Transfer} period.

The Technology Assessment document was submitted during the previous reporting

\subsubsection{Meetings}

A kickoff and project update meeting was held with Richard Baker from DOE at SwRI in May 2004.

\subsubsection{Deliverables}

Documents were delivered as per the project schedule. These included the Research Management Plan, Technology Assessment, Hazardous Substance Plan, Semi-Annual Technical Progress Report No. 1, Informal Status Reports, Financial Status Reports, and Federal Cash Transaction Reports. 


\subsubsection{Milestones}

Project milestones are shown in the following table. The Modeling and Simulations and Parameter Optimization milestones are considered completed, although some additional work will continue in order to support the Pipeline Testing task. The Contact Simulator milestone is also complete. The CP Interactions milestone is being extended in order to allow time to analyze data from operating pipelines and to have further discussions with $\mathrm{CP}$ experts. None of the other milestone dates are projected to change.

\begin{tabular}{|l|c|c|}
\hline \multicolumn{1}{|c|}{ Milestone } & Due Date & Revised Due Date \\
\hline Modeling and Simulations Completed & Complete & \\
\hline Parameter Optimization Completed & Complete & \\
\hline CP Interactions Determined & $8 / 2 / 04$ & $12 / 31 / 04$ \\
\hline Contact Simulator Completed & Complete & \\
\hline Pipeline Testing Completed & $6 / 1 / 05$ & \\
\hline System Demonstration & $6 / 1 / 05$ & \\
\hline Data Evaluation Completed & $8 / 1 / 05$ & \\
\hline Design Guidelines Completed & $8 / 1 / 05$ & \\
\hline
\end{tabular}

\section{WORK ANTICIPATED IN NEXT REPORTING PERIOD}

In the next reporting period, additional testing will be performed on operating pipelines. This will include testing of the IACC method over longer operating distances and different soil conditions. In addition, soil and pipe parameters under different conditions will be measured with the goal of understanding these conditions and improving the IACC system operating parameters and signal-processing method. Additional measurements will be conducted with active and passive CP systems connected to further determine their effect. CP system experts will evaluate the potential effects of IACC signals on CP, as well as provide additional details about how CP systems may affect IACC.

\section{CONCLUSIONS}

The IACC method is promising as a monitoring method for third-party contact. Initial tests on an operating pipeline showed that IACC signals were detectable up to a distance of 3,634 feet. Future tests over longer distances and with different pipe, soil, and cathodic protection system parameters will determine the overall viability and potential of the technique as a practical system.

\section{REFERENCES}

[1] Marshall, J. L., Lightning Protection (New York: John Wiley \& Sons, 1973), 37-79.

[2] Carpenter, R. B., Jr., and J. A. Lanzoni, "Designing for a Low Resistance Earth Interface (Grounding)," an LEC publication, revised July 1997. 